\title{
Pathogenetic aspects of chronic urticaria. Retrospective and prospective analysis of the patients of the Department of Dermatology, Poznan University of Medical Sciences
}

\author{
Dorota Jenerowicz' ${ }^{1}$ Anna Błaszczyk ${ }^{1}$, Filip Raciborski², Anna Sadowska-Przytocka ${ }^{1}$, Zygmunt Adamski ${ }^{3}$, \\ Magdalena Czarnecka-Operacz ${ }^{1}$
}

\begin{abstract}
1Department of Allergic and Occupational Skin Diseases, Poznan University of Medical Sciences, Poznan, Poland ${ }^{2}$ Department of Prevention of Environmental Hazards and Allergology, Medical University of Warsaw, Warsaw, Poland ${ }^{3}$ Department of Dermatology, Poznan University of Medical Sciences, Poznan, Poland
\end{abstract}

Adv Dermatol Allergol 2022; XXXIX (3): 587-593

DOI: https://doi.org/10.5114/ada.2021.107270

\begin{abstract}
Introduction: Urticaria is a disease with a complex pathomechanism. Confirmation of the cause in chronic urticaria seems to be a great challenge for specialists.

Aim: To assess the frequency of different types of urticaria and their coexistence in 1 patient, diseases associated with chronic urticaria and the frequency of accompanying oedema.

Material and methods: The study was divided into two parts. Retrospective analysis included 441 chronic urticaria patients at the age of 15 or older hospitalized in 10 years. Information from history of the disease has been placed in a specially designed form. For the prospective analysis 78 patients have been chosen out of 441 subjects previously qualified for retrospective analysis.

Results: The most common type of urticaria was autoimmune (27.9\% R; 30.8\% P), spontaneous (19.3\% R; 39.7\% P) and aspirin-induced urticaria $(17.5 \% \mathrm{R} ; 25.6 \% \mathrm{P})$. The most common coexisting types of urticaria were autoimmune with aspirin-induced $(7.5 \% \mathrm{R} ; 10.3 \% \mathrm{P})$ and autoimmune with dermographic urticaria $(3.2 \% \mathrm{R} ; 5.1 \% \mathrm{P})$. In more than half of the patients (66.7\%) one type occurs only. Angioedema coexisted in over half of the patients ( $58 \%$ R; $69.2 \%$ P) Among the coexisting comorbidities in people with accompanying angioedema, statistically significant differences appeared in patients with thyroid diseases (19.9\% with oedema and $4.9 \%$ without oedema). Among drug users, there was a greater difference between the percentage of patients with or without angioedema than among non-drug users.

Conclusions: It was found that among the inducing factors - pressure and stress and among drugs taken for diseases other than urticaria - NSAIDs had an influence on the persistence of symptoms in P patients.
\end{abstract}

Key words: chronic urticaria, angioedema, pathogenesis.

\section{Introduction}

Urticaria is a disease with a complex pathomechanism which is characterized by the occurrence of wheals, oedema or both at the same time. Skin changes are accompanied by pruritus and/or sometimes burning sensation. Different types of urticaria have a very wide range of clinical manifestations and in one patient more than one of its types may coexist.

Confirmation of the cause in chronic urticaria seems to be a great challenge for specialists. Before selecting tests, all regional and dietary diversity as well as the incidence of infection should be taken into account. According to EAACl/ GA2LEN/EDF/WAO guidelines from 2017, the first stage of diagnosis is a very detailed interview with the patient. The next step is physical examination, which should include challenge tests selected based on the interview.

\section{Aim}

The aims of the study were to assess the frequency of different types of urticaria and their coexistence in

Address for correspondence: Anna Błaszczyk, Department of Allergic and Occupational Skin Diseases, Poznan University of Medical Sciences, Poznan, Poland, phone: +48 507860 311, e-mail: a.noowak@gmail.com Received: 13.04 .2021 , accepted: 25.04.2021. 
one patient, evaluate diseases associated with chronic urticaria and assess the frequency of accompanying oedema.

\section{Material and methods}

The study was divided into two parts - the retrospective one $(R)$ and the prospective one $(P)$. Patients from $P$ part were divided into subgroup I and II in terms of persistence of symptoms.

Retrospective analysis included 441 chronic urticaria patients at the age of 15 or older hospitalized at the Department of Dermatology, Poznan University of Medical Sciences in 10 years. The study analysed history of the disease of all patients and then anonymised information has been placed in a specially designed form. For the prospective analysis 78 patients have been chosen out of 441 subjects previously qualified for retrospective analysis, suffering from chronic aspirin-exacerbated disease, spontaneous, autoimmune and induced urticaria. Statistical analysis was carried out in the IBM SPSS program (ver. 23).

\section{Results}

The most common type of urticaria in R part was autoimmune (27.9\%), followed by spontaneous (19.3\%), aspirin-induced (17.5\%), dermographic urticaria (10.0\%) and in P part - spontaneous (39.7\%), autoimmune (30.8\%), aspirin-induced (25.6\%), delayed-pressure (14.1\%) and dermographic urticaria (11.5\%) (Figure 1).

Among the coexisting types of urticaria, the most common type was autoimmune with aspirin-induced urticaria (7.5\% in R and $10.3 \%$ in P), autoimmune with dermographic urticaria (3.2\% in R and 5.1\% in P), autoimmune with delayed pressure urticaria (2.7\% in R), aspirininduced with dermographic urticaria $(2.7 \%$ in $\mathrm{R}$ and $5.1 \%$ in $\mathrm{P}$ part), and aspirin-induced with cholinergic urticaria $(2.0 \%$ in $\mathrm{R})$.

We also evaluated the coexistence of different types of urticaria in 1 patient, which shows that in more than half of the patients (66.7\% in R and $\mathrm{P}$ part) occurs only one type, in $23.3 \%$ in $R$ and $18.7 \%$ in $P-2$; in $8.5 \%$ in $R$ and $12 \%$ in $P-3$; in $1.2 \%$ in $R$ and $2.7 \%$ in $P-4$ and in only one person in $\mathrm{R}$ part $(0.3 \%)-5$ types.

In over $45 \%$ of patients, the potential cause of the symptoms could not be identified. However, in $21.1 \%$ there were drugs (acetylsalicylic acid), in 12.9\% - food, and in $10.9 \%$ - pressure. The evaluation in $\mathrm{P}$ part presented very similar results..

Most respondents from $R$ part presented symptoms of urticaria every day (35.2\%). However, patients from subgroup I (still suffering from urticaria) in P part - several times a week (30.2\%).

The most frequent (daily) symptoms of urticaria appeared in patients with dermographic (47.8\%), autoimmune (47.4\%) and aspirin-induced urticaria (44.7\%) (Figure 2).

Angioedema coexisted with urticaria in over half of the patients (58\% in R and $69.2 \%$ in P). It most often coexisted in patients with aspirin-induced (76.6\%), autoimmune (68.3\%) and spontaneous urticaria (62.4\%). It occurred predominantly in women (62\%) and in the $>55$ years age group (65.4\%), also in people living in rural areas $(63.6 \%)$ (Figure 3$)$.

In $36.7 \%$ of all patients in $\mathrm{R}$ part there were no additional medical conditions. The other patients, apart from urticaria, most often presented symptoms of: hyperten-

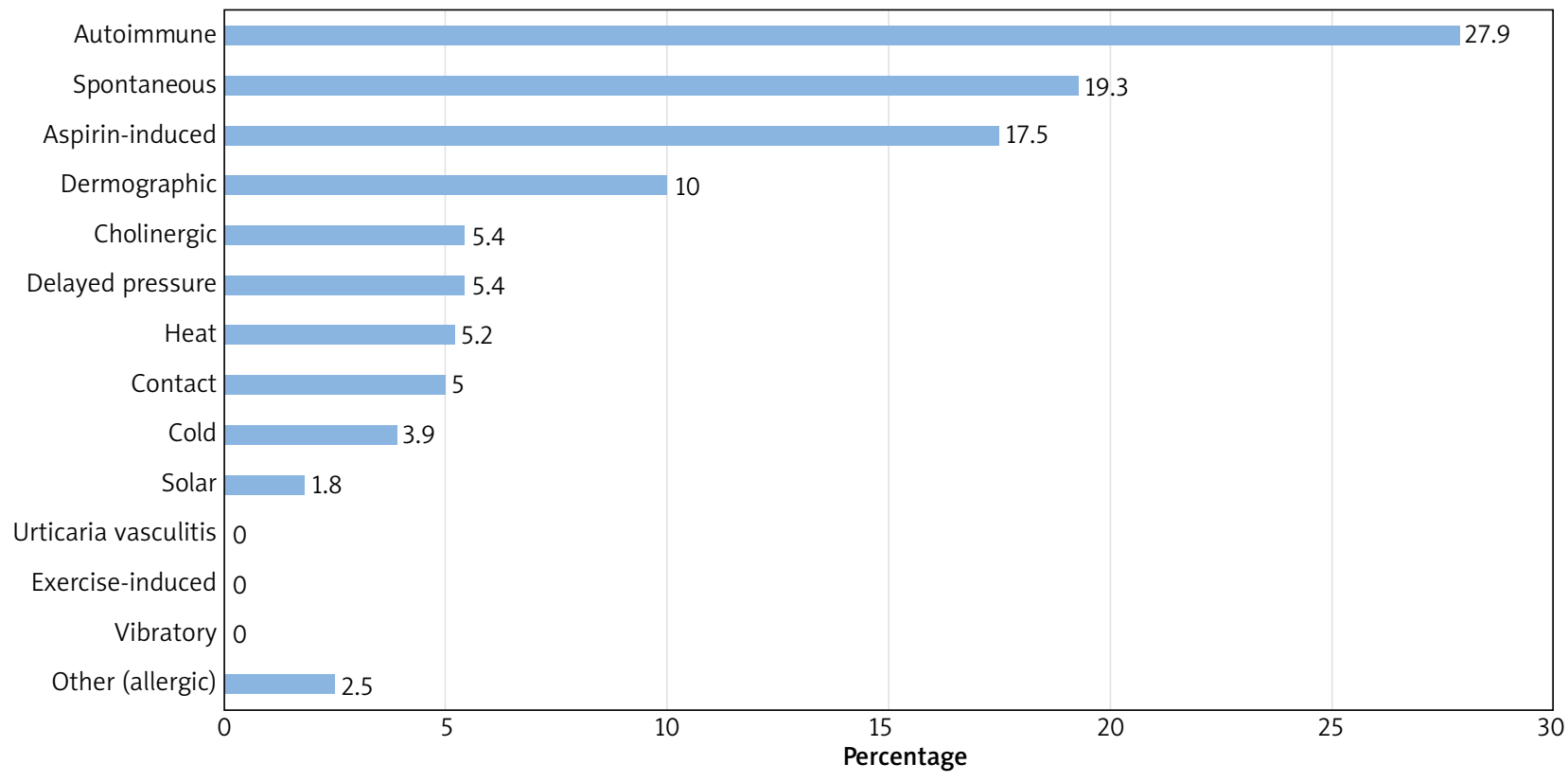

Figure 1. Most common types of urticaria (R part) 


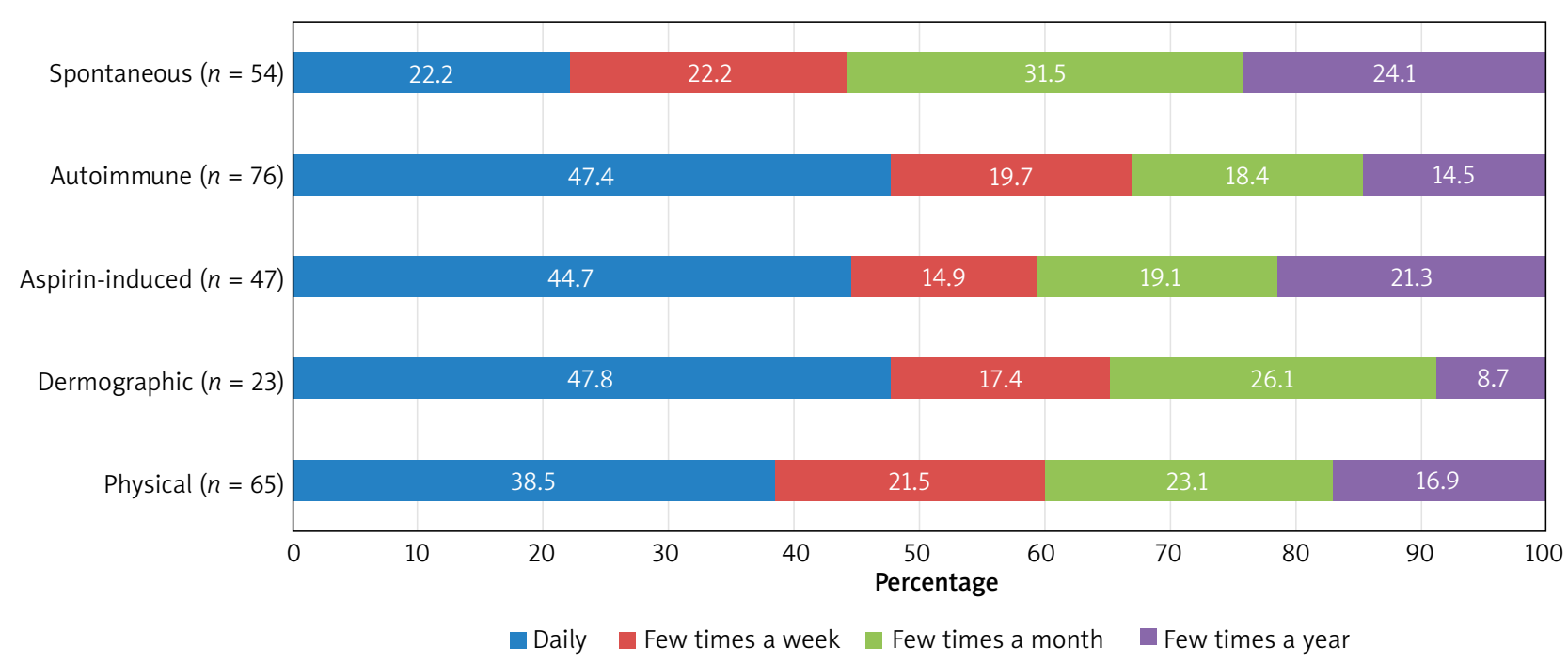

Figure 2. Frequency of the occurrence of wheals in different types of urticaria (R part)

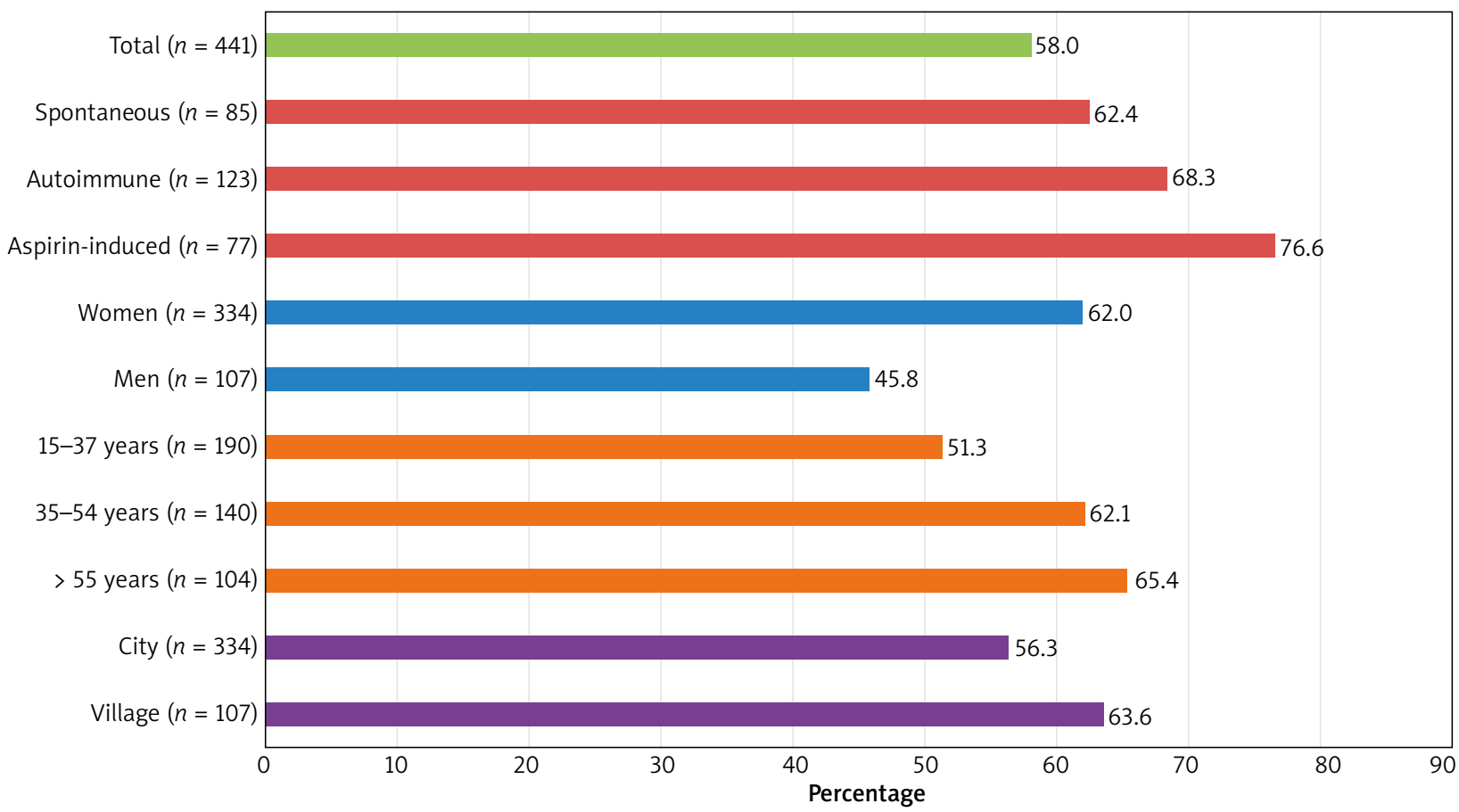

Figure 3. Coexistence of angioedema in selected subgroups ( $R$ part)

sion (19.3\%), atopy (16.3\%), thyroid diseases (13.6\%), and chronic infections and inflammations (8.6\%). The following were most commonly reported in $\mathrm{P}$ part: thyroid disease (19.2\%), hypertension (16.7\%) and atopy (11.5\%).

The coexistence of accompanying diseases was also evaluated in 256 patients of $\mathrm{R}$ part with accompanying angioedema in comparison with 185 patients without an- gioedema. Statistically significant differences appeared in patients with thyroid diseases (19.9\% with oedema and $4.9 \%$ without oedema) (Figure 4).

The most common medications for diseases other than urticaria used by patients in R part were antihypertensive drugs (18.6\%) and hormones - including thyroid hormones - (16.8\%). Other dominant drugs are drugs af- 


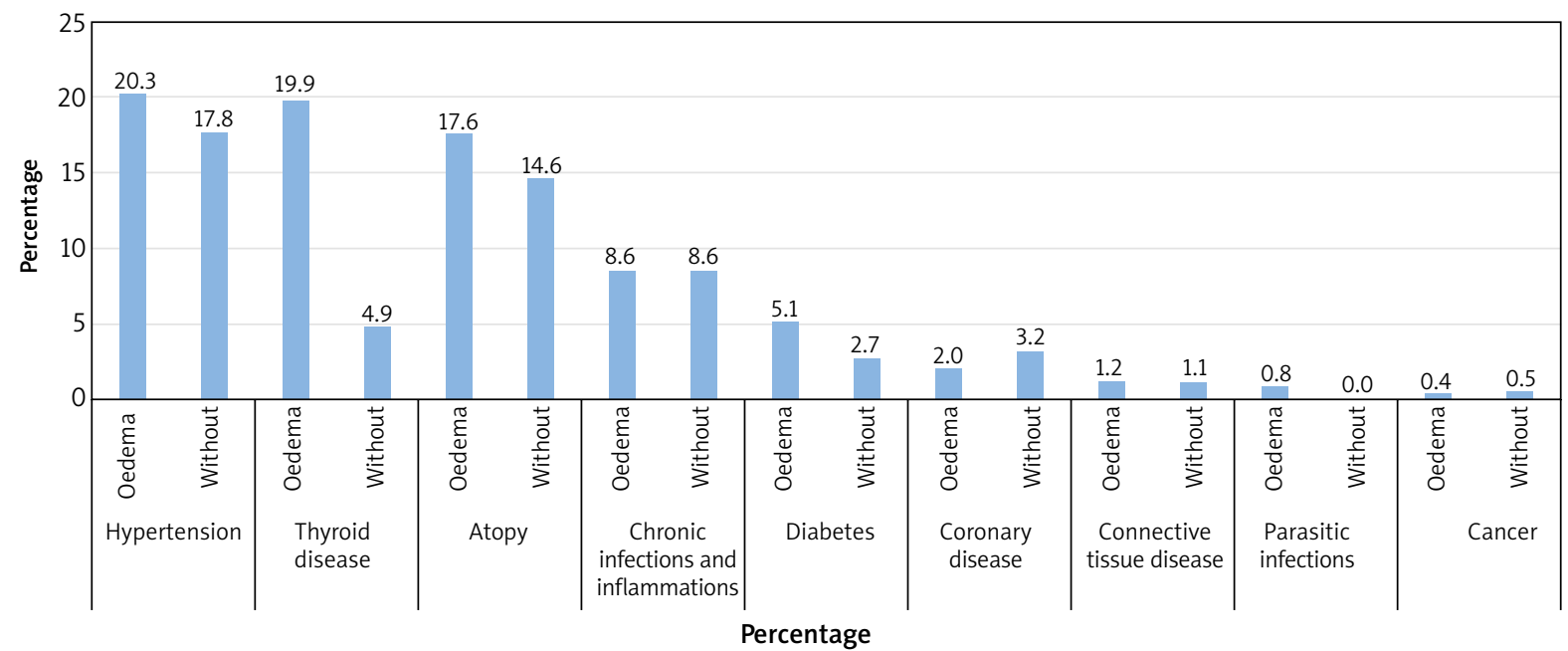

Figure 4. Coexistence of comorbidities in people with accompanying angioedema ( $N=256-$ angioedema, $N=185-$ no angioedema)

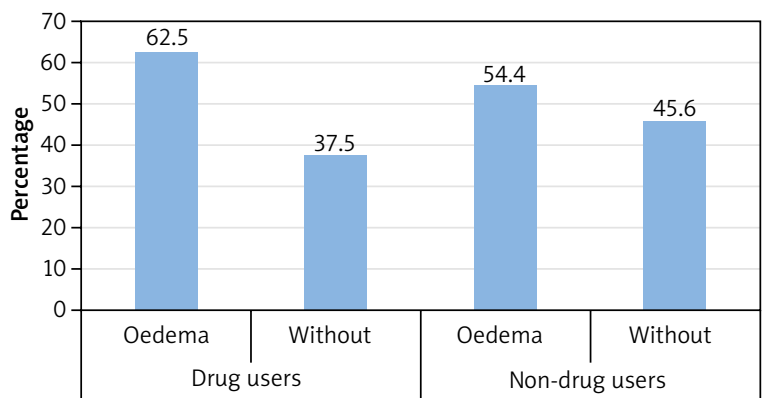

Figure 5. Coexistence of angioedema in drug users $(N=200)$ and non-drug users $(N=237)$

fecting the CNS (7.3\%) and proton-pump inhibitors (5\%). In $\mathrm{P}$ part hormones were most often used - including thyroid hormones - (24.4\%), then antihypertensive drugs (16.7\%), NSAIDs (12.8\%), but also psychotropic drugs (7.7\%).

We have also performed the analysis of the coexistence of angioedema in patients of $R$ part using medications $(N=200)$ and not using medications ( $N=237)$. Four people with no information in this field were excluded from the analysis. Among drug users, there was a greater difference between the percentage of patients

Table 1. The frequency of symptoms as a result of pressure, emotional stress and NSAIDs in subgroups I and II (P part)

\begin{tabular}{lcccccc}
\hline \multirow{2}{*}{ Subgroup } & \multicolumn{3}{c}{ Pressure (\%) } & \multicolumn{2}{c}{ Stress (\%) } & \multicolumn{2}{c}{ NSAIDs (\%) } \\
\cline { 2 - 7 } & No & Yes & No & Yes & No & Yes \\
\hline I & 47.5 & 82.4 & 50.0 & 100.0 & 50.0 & 90.0 \\
\hline II & 52.5 & 17.6 & 50.0 & 0.0 & 50.0 & 10.0 \\
\hline
\end{tabular}

with or without angioedema than among non-drug users (Figure 5).

The family history of atopy and urticaria in the vast majority of respondents was negative $(85.7 \%$ in $\mathrm{R}$ and $84.6 \%$ in $\mathrm{P})$.

More than half of the patients with chronic urticaria did not undergo any procedures or operations (64.6\% in $R$ and $59 \%$ in $P$ ).

In $73 \%$ of R patients, no latent infections were detected, however $13.6 \%$ presented ENT problems, $11.5 \%$ - dental, 5.5\% - problems related to inflammation in the abdominal cavity and only $2.8 \%$ - gynaecological problems.

In R patients with laryngological problems, symptoms appear most often (every day -34.4\%) and only several times a year (37.1\%) - in patients with dental foci.

It was found that among the inducing factors, pressure and stress and among drugs taken for diseases other than urticaria, NSAIDs had an influence on the persistence of symptoms in $P$ patients. There was a significant difference in the frequency of the above-mentioned factors between subgroups I and II (Table 1).

\section{Discussion}

The results of the research are similar to the available results of other epidemiological studies. All of them confirmed that spontaneous urticaria was the most common type. The Spanish authors indicated that $75 \%$ and $68 \%$ of the respondents have spontaneous urticaria [1, 2], Chinese - 68.1\% [3], Brazilian and Portuguese - 25\% [4], Singaporean - 89.3\% [5], and Arab-44.3\% [6]. Such results confirm the thesis that in many cases it is very difficult to determine the cause of the occurrence of urticaria and it may be related to a different diagnostic approach. Most 
analyses do not include autoimmune and aspirin-induced urticaria in the classification.

In the R part of the study, the most common physical urticaria was dermographic (10\%), then delayed pressure (5.4\%) and heat urticaria (5.2\%). However, the P part indicated that the most frequent urticaria was delayed pressure (14.1\%), followed by dermographic (11.5\%) and heat urticaria (6.4\%). Both results are in line with the available publications [7-9]. Jankowska-Konsur et al. [10] pointed to dermographic urticaria (11.7\%) as the most common among inducible types. Valero et al. [2] reported that the most common type among adult Spaniards was delayed pressure (22\%), dermographic (21\%) and solar urticaria (8\%), which is most likely due to climatic differences and a high level of insolation in Spain. For comparison, in the current study, solar urticaria was one of the rarest types (1.8\% in $\mathrm{R}$ and $1.3 \%$ in $\mathrm{P})$. The diagnosis of solar urticaria is quite difficult and carries the risk of confusion with another photodermatosis. Some studies [6, 11, 12] indicated cold urticaria as a quite frequent type, however in the current study this type was placed lower in the classification ( $R-3.9 \%$ and $P-5.1 \%)$.

Numerous reports emphasize the possibility of coexistence of different types of chronic urticaria. Schoepke et al. [9] reported that in $21 \%$ of all patients with dermographic urticaria, another type was also detected. Most often it was spontaneous urticaria, which is consistent with the results obtained, considering that autoimmune urticaria is a subtype of spontaneous urticaria. Cassano et al. [13] also reported a high probability of coexistence of delayed pressure urticaria with dermographic urticaria (>50\%).

In both parts of the study, in most cases it was not possible to establish a clear cause of the symptoms. Then, it was positive ASST and medications, which coincides with most common urticarias among the respondents (spontaneous, autoimmune and aspirin). In the $P$ part, emotional stress was a very common cause, however in the $\mathrm{R}$ it was considered the rarest cause. Perhaps patients at home noticed a greater correlation between stressful situations and wheals than the attending physicians during a time-limited hospitalization. In many cases, no information was provided on the potential cause of the symptoms, which prompts consideration of the particular importance of the medical interview as a useful diagnostic tool in patients with chronic urticaria.

Greaves [14] mentioned hypersensitivity to ASA and autoantibodies as the most common cause of chronic urticaria. Henz et al. [15] confirmed the autoimmune background in $30 \%$ of patients, and food and drug intolerance in $25 \%$. In a study conducted among the Chinese population, the causes in $21.6 \%$ and $4 \%$ of patients were food and drug allergies, respectively, while in as much as $72.1 \%$ the cause was temperature changes [3]. Mazur et al. [16] also pointed to food and drugs as the most frequently mentioned causes.
Autoimmune and dermographic urticaria were the most common types, which is certainly due to the difficulties in elimination of the causative agent in these types of CU, and in the autoimmune urticaria, it is virtually impossible within a certain time frame. The statistically significant results concerning the frequency of the occurrence of skin changes related to the triggering factor appeared in relation to food, medications and physical factors. However, most often the skin changes occurred in patients in whom dietary components were a potential causative factor.

Currently, it is assumed that angioedema accompanies about half of the patients with CU. The lowest coexistence was reported in Germany by Weller et al. [17] - 19\% and in the Arabic study [6] - 19.7\% of all patients with CU. The results below $40 \%$ were also presented in the Spanish [1] - 30.8\% or Italian analysis [18] - 36\%. The Chinese reported 47.3\% [3], while Brazilians 50.4\% [19]. Such varied results may demonstrate a lack of consistency in the diagnosis of angioedema. Most of the analyses concerning the location of the oedema are definitely consistent with the current study.

Oedema accompanied aspirin-induced urticaria more often than the other types. Perhaps this is due to the fact that aspirin may both induce and exacerbate angioedema and urticaria. Oedema definitely dominated in women and in patients at the age of $>55$. Łukaszyk et al. [20] made similar observations. Angioedema also appeared more frequently in patients living in the countryside, which may be related to the exposure to different and more predisposing factors than urban ones.

Chronic urticaria is often associated with other diseases. Many researchers analysed mainly allergic diseases accompanying urticaria. Rosman et al. [21] reported that food allergy was the most common, followed by $A D$ and allergic rhinitis. Fatani et al. [6] and JankowskaKonsur et al. [10] also concluded that atopy is one of the most common comorbidities. Ferrer [1] reported that Spanish patients mainly suffered from autoimmune diseases, connective tissue, endocrine and myeloproliferative diseases, and only a few suffered from chronic infections.

The role of the pathogenetic importance of anti-thyroid antibodies and thyroid disease in chronic urticaria remains controversial [22]. Italian researchers in their recent epidemiological study did not notice a statistically significant relationship between the occurrence of thyroid diseases and CSU [23]. However, many authors reported a high percentage of patients with concomitant diseases of the thyroid gland [21, 24-29]. Ferrer [1] confirmed the relationship between the occurrence of chronic urticaria and autoimmune thyroid diseases. Other reported much lower rates of this coexistence, but recommended this gland to be tested during routine diagnosis [30]. 
In the R part the coexistence of comorbidities was also analysed in connection with the presence of angioedema. Statistically significant results concerned thyroid diseases, where $19.9 \%$ of the patients with oedema suffered from thyroid diseases, compared with $4.9 \%$ of the non-oedema patients suffering from thyroid gland diseases. Łukaszyk et al. [20] determined in their publication that the most common diseases associated with angioedema were: arterial hypertension, thyroid disease and diabetes. On the other hand, Madsen et al. [31] reported that among Danish oedema patients, the most common disease was sinusitis, HSV infection, connective tissue diseases and cystitis.

Most of the foreign publications do not present any results concerning medications taken for conditions other than urticaria which may influence the appearance of urticaria. There were only reports of exacerbations caused by taking medications $[1,3,19]$. It is worth mentioning the relatively frequent use of psychotropic drugs and drugs affecting the central nervous system by patients in this paper.

Part $R$ also evaluated whether the use of drugs may affect the occurrence of episodes of angioedema. It can be seen that there was a much greater difference in the percentage of patients with and without oedema among drug users than among non-drug users. Other Polish authors noted that in the group of hospitalized patients with urticaria and oedema, NSAIDs and antibiotics were the most common causes of symptoms [20].

In all publications, where family history was analysed, it was exclusively related to atopy. Most of the researchers' results are consistent with those obtained in our own analysis. Fatani et al. [6] reported that the total negative family history of patients with atopic diseases was 73.1\%. Heng et al. [5] reported a negative history in $68.9 \%$. Only the Brazilian authors noted a slight difference between positive and negative family history [19]. It turned out that almost half of the patients (44.8\%) had allergic diseases in the family.

Epidemiological publications on chronic urticaria available so far do not deal with the impact of the procedures performed by the patient on the occurrence of disease symptoms. In this paper, there was no significant influence of surgery and other operations on the occurrence of the lesions.

Dental and laryngological inflammations had a significant influence on the frequency of the occurrence of symptoms. The other authors presented some discrepancies in their results. Chinese authors reported the presence of inflammations in the abdominal cavity in $10 \%$ of the population, ENT in $1.6 \%$ and urogenital in $0.7 \%$ [3]. Quite the opposite, Kacalak-Rzepka et al. [32] noted a much higher percentage $(35.6 \%)$ of the presence of latent infections, including $27.8 \%$ of patients presenting hidden sources of infection in the abdominal cavity, $2.9 \%$ dental, 3.8\% laryngological, and 0.9\% urogenital. German researchers also identified ENT problems in almost 50\% of patients [33].

\section{Conclusions}

The results obtained in this analysis were in varying agreement with the available world reports on various aspects of chronic urticaria. These interesting areas deserve further analysis.

\section{Conflict of interest}

The authors declare no conflict of interest.

\section{References}

1. Ferrer M. Epidemiology, healthcare, resources, use and clinical features of different types of urticaria. Alergologica 2005. J Investig Allergol Clin Immunol 2009; 19: 21-6.

2. Valero A, Herdman M, Bartra J, et al. Adaptation and validation of the Spanish version of the Chronic Urticaria Quality of Life Questionnaire (CU-Q2oL). J Investig Allerol Clin Immunol 2008; 18: 426-32.

3. Zhong H, Song Z, Chen W, et al. Chronic urticaria in Chinese population: a hospital-based multicenter epidemiological study. Allergy 2014; 69: 359-64.

4. Dias GAC, Pires GV, Rodrigues de Valle SO, et al. Cross-cultural adaptation of the Brazilian-Portuguese version of the chronic urticaria quality-of-life questionnaire - CU-Q2oL. Allergy 2011; 66: 1487-93.

5. Heng JK, Koh LJ, Toh MP, et al. A study of treatment adherence and quality of life among adults with chronic urticaria in Singapore. Asia Pac Allergy 2015; 5: 197-202.

6. Fatani MI, Bahashwan E, Alfif KA, et al. The prevalence of urticaria and its clinical patterns in Makkah, Saudi Arabia. J Health Sci 2015; 5: 6-9.

7. Breathnach SM, Allen R, Ward AM, et al. Symptomatic dermographism: natural history, clinical features laboratory investigations and response to therapy. Clin Exp Dermatol 1983; 8: 463-76.

8. Kontou-Fili K, Borici-Mazi R, Kapp A, et al. Physical urticaria: classification and diagnostic guidelines. An EAACI position paper. Allergy 1997; 52: 504-13

9. Schoepke N, Młynek A, Weller K, et al. Symptomatic dermographism: an inadequately described disease. J Eur Acad Dermatol Venereol 2015; 29: 708-12.

10. Jankowska-Konsur A, Reich A, Szepietowski J, et al. Clinical characteristics and epidemiology of chronic urticaria: a nationwide, multicentre study on 1091 patients. Adv Dermatol Allergol 2019; 36: 184-91.

11. Marciniak A, Wegner J, Czarnecka-Operacz M. Problem eozynofilii w pokrzywce przewlekłej. Adv Dermatol Allergol 2006; 23: 5-11.

12. Singleton R, Caroline P, Halverstam CP. Diagnosis and management of cold urticaria. Cutis 2016; 97: 59-62.

13. Cassano N, Mastrandrea V, Vestita M, et al. An overview of delayed pressure urticaria with special emphasis on pathogenesis and treatment. Dermatol Ther 2009; 22: 22-6.

14. Greaves M. Chronic urticaria. J Allergy Clin Immunol 2000; 105: 664-72.

15. Henz BM, Zuberbier T, Monroe E. Dietary management of chronic urticaria. In: Urticaria, clinical, diagnostic and thera- 
peutic aspects. Henz BM, Zuberbier T, Grabbe J, Monroe E (eds.). Springer, Berlin 1998: 163-8.

16. Mazur M, Czarnobilska M, Czarnobilska E. Prevalence and potential risk factors of urticaria in the Polish population of children and adolescents. Adv Dermatol Allergol 2020; 37: 785-9.

17. Weller K, Grattan C, Hollis K, et al. ASSURE-CSU, burden of illness study in CSU patients: dermographics and clinical characteristics from UK, Canada and Germany. Presented at the European Academy of Allergy and Clinical Immunology (EAACI), Barcelona, Hispan, 6-10 June 2015.

18. Małolepszy J. Reminiscencje na temat alergologii polskiej. Adv Dermatol Allergol 2009; 26: 286-92.

19. Silvares MRC, Rabello Coelho KI, Dalben I, et al. Sociodemographic and clinical characteristics, casual factors and evolution of a group of patients with chronic urticaria-angioedema. Sao Paulo Med I 2007; 125: 281-5.

20. Łukaszyk M, Łukaszyk E, Kozłowska D, et al. Profil kliniczny i przyczyny występowania obrzęku naczynioruchowego wśród pacjentów hospitalizowanych w klinice uniwersyteckiej. Alerg Astma Immun 2015; 20: 101-5.

21. Rosman Y, Hershko AY, Meir-Shafrir K, et al. Characterization of chronic urticaria and associated conditions in a large population of adolescents. J Am Acad Dermatol 2019; 81: 129-35.

22. Kaplan AP, Greaves M. Pathogenesis of chronic urticaria. Clin Exp Allergy 2009; 39: 777-87.

23. Lapi F, Cassano N, Pegoraro V, et al. Epidemiology of chronic spontaneous urticaria: results from a nationwide, population-based study in Italy. Br J Derm 2016; 174: 996-1004.

24. Hyman SJ, Shreffler WG, Rapaport R. Type 1 diabetes, autoimmune thyroid disease, and chronic urticaria. Pediatr Diabetes 2008; 9: 508-11.

25. Levy Y, Segal N, Weintrob N, et al. Chronic urticaria: association with thyroid autoimmunity. Arch Dis Child 2003; 88: 517-9.

26. Nowak A, Jenerowicz D, Czarnecka-Operacz M. Jakość życia u chorych na pokrzywkę przewlekłą. Wiad Dermatol 2014; 3: 7-9.

27. Rumbyrt JS, Schocket AL. Chronic urticaria and thyroid disease. Immunol Allergy Clin North Am 2004; 24: 215-23.

28. Turktas I, Gokcora N, Demirsoy S, et al. The association of chronic urticaria and angioedema with autoimmune thyroiditis. Int J Dermatol 1997; 36: 187-90.

29. Verneuil L, Leconte C, Ballet JJ, et al. Association between chronic urticaria and thyroid autoimmunity: a prospective study involving 99 patients. Dermatology 2004; 208: 98-103.

30. Pan XF, Gu JQ, Shan ZY. The prevalence of thyroid autoimmunity in patients with urticaria: a systemic review and metaanalysis. Endocrine 2015; 48: 804-10.

31. Madsen F, Atterman J, Linneberg A. Epidemiology of nonhereditary angioedema. Acta Derm Venerol 2012; 92: 475-9.

32. Kacalak-Rzepka A, Kiedrowicz M, Bielecka-Grzela S, et al. Pokrzywka przewlekła jako potencjalny wskaźnik choroby ogólnoustrojowej. Przegl Dermatol 2010; 97: 319-28.

33. Buss YA, Garrelfs UC, Sticherling M. Chronic urticaria - which clinical parameters are pathogenetically relevant? A retrospective investigation of 339 patients. J Dtsch Dermatol Ges 2007; 5: 22-7. 